\title{
Elevated expression of proprotein convertases alters breast cancer cell growth in response to estrogen and tamoxifen
}

\section{Cheng, N Xu, B Iwasiow, N Seidah ${ }^{1}$, M Chrétien $^{2}$ and R P C Shiu}

Department of Physiology, Faculty of Medicine, University of Manitoba, Winnipeg, Manitoba, Canada

${ }^{1}$ Clinical Research Institute of Montreal, Montreal, Quebec, Canada

${ }^{2}$ Loeb Health Research Institute, Ottawa Hospital, Ottawa, Ontario, Canada

(Requests for offprints should be addressed to R P C Shiu, Department of Physiology, University of Manitoba, 770 Bannatyne, Winnipeg, Manitoba, Canada R3E 0W3; Email: rshiu@cc.umanitoba.ca)

\begin{abstract}
Two proprotein convertase cDNAs, PC1 and furin, were stably transfected into the human breast cancer cell line MCF-7. The PC1 or furin over-expressing cells possessed an altered morphology. When grown in vitro in a serum-free medium, the population doubling time of the convertase-transfected cells was twice that of wild-type (WT) cells. High concentrations of estradiol stimulated the growth of all three cell types to a similar extent; however, at low concentrations of estradiol, the convertase-transfected cells grew more slowly than W'T cells. In athymic nude mice implanted with $5 \mathrm{mg}$ estradiol pellets, the growth of tumors of convertase-transfected MCF-7 cells was
\end{abstract}

stimulated to a degree similar to that of WT MCF-7 tumors. However, in mice implanted with lower-dose $(1.5 \mathrm{mg})$ estradiol pellets, the tumors of PC1- or furin-transfected MCF-7 cells grew approximately five times slower than those of WT MCF-7 cells. In mice implanted with tamoxifen pellets, tumors of PC1 - or furin-transfected MCF-7 cells regressed approximately five times slower than the WT tumors. This study shows that the over-expression of proprotein convertases confers a greater estrogen dependency and anti-estrogen resistance on human breast cancer cells.

Fournal of Molecular Endocrinology (2001) 26, 95-105

\section{INTRODUCTION}

The abnormal expression of autocrine or paracrine growth factors, together with oncogenes, might play a major role in human breast cancer progression (Dickson \& Lippman 1995). Many growth factors (such as epidermal growth factor, transforming growth factors $\alpha$ and $\beta$, insulin-like growth factors I and II) and receptors (such as insulin-like growth factor receptor type I, Neu and integrin) have been shown to be generated from their inactive precursors by the actions of proprotein convertases, or to contain potential processing sites for proprotein convertases (Mbikay et al. 1993). Thus, an altered expression of proprotein convertases could profoundly influence the growth characteristics of breast cancer and other cancers by changing the production or availability of biologically active growth regulators.

Proprotein convertases, also known as prohormone convertases, are a family of serine proteinases of the subtilisin/kexin type. To date, eight known mammalian convertases have been named, as follows: PC1 (also called PC3), PC2, PC4, PC5 (also called PC6), PC7 (also called PC8, LPC and SPC7), furin (also called PACE) and PACE4 (Steiner et al. 1992, Seidah et al. 1998), and SKI-1, the most recently cloned isozyme (Seidah et al. 1999).

Elevated expression of proprotein convertase members in human lung (Schalken et al. 1987, Mbikay et al. 1997) and breast cancers (Scopsi et al. 1995, Cheng et al. 1997) has been documented. Also, PC7 has been identified at a chromosome translocation break point in a human lymphoma (Meerabux et al. 1996). The over-expression of PACE4 via gene transfection in mouse squamous cell carcinoma resulted in enhanced tumor-cell invasiveness (Hubbard et al. 1997). Finally, the observation that the breast cancer susceptibility gene products (BRCA1 and BRCA2) contain numerous potential convertase cleavage sites (Steeg 1996) strongly suggests an important role for proprotein convertases in human breast tumorigenesis. Taken together, the 
above findings provide a compelling argument for an important role of the proprotein convertase family of genes in human cancer development and progression.

To gain further insight into the biological functions of proprotein convertases in human breast cancer, we have generated, via gene transfection, MCF-7 human breast cancer cell lines that over-express either one of the two proprotein convertases, PC1 and furin. Here we report that MCF-7 cells over-expressing PC1 or furin possess both an altered cell shape in vitro and an altered growth behaviour in vitro and in vivo in athymic nude mice in response to estrogen and the antiestrogen tamoxifen.

\section{MATERIALS AND METHODS}

\section{Gene transfection of MCF-7 cells}

Full-length cDNAs for mouse PC1 (mPC1) and human furin (hfurin) cloned into the expression vector pcDNA3 were linearized with ScaI before being transfected into MCF-7 human breast cancer cells by using calcium phosphate (Mammalian Transfection Kit and protocol, Stratagene, La Jolla, CA, USA). MCF-7 cells were also transfected with ScaI-linearized pcDNA3 vector alone and these cells were used as control cells. Cell culture conditions were as previously described (Cheng et al. 1997). Neomycin-resistant colonies that emerged from single cells in the presence of $1 \mathrm{mg} / \mathrm{ml} \mathrm{G}-418$ (Geneticin; Gibco/BRL Life Technologies, Grand Island, NY, USA) in the culture medium were picked by using sterile Whatman (Fischer Scientific, Pittsburg, PA, USA) filter-paper discs saturated with trypsin/EDTA solution, transferred to 96-well plates and subsequently expanded. MCF-7 clones were analyzed by Southern blotting (for transgene integration), by Northern blotting (for mRNA expression) and by immuno-precipitation or Western blotting (for protein production).

\section{Southern and Northern blot analyses}

Genomic DNA was isolated from MCF-7 cell clones as described previously (Hogan et al. 1986). For Southern analysis, $10 \mu \mathrm{g}$ DNA was first digested with the appropriate restriction endonucleases (PstI for mPC1-transfected cells, and BamHI+BglII for hfurin-transfected cells). Hybridization with ${ }^{32} \mathrm{P}$-labeled $\mathrm{mPC1}$ or hfurin cDNA was carried out using conditions described previously (Maniatis et al. 1989).

Total RNA was isolated from MCF-7 cells as described previously (Cheng et al. 1997), and $30 \mu \mathrm{g}$ of each sample was subjected to Northern blot analysis (Maniatis et al. 1989).

\section{Immunoprecipitation}

MCF-7 cells were labeled with $100 \mu \mathrm{Ci} / \mathrm{ml}$ $\left[{ }^{35} \mathrm{~S}\right]$ cysteine $(800 \mathrm{Ci} / \mathrm{mmol}$; ICN Biomedical Research Products, Costa Mesa, CA, USA) for $24 \mathrm{~h}$ in Dulbecco's modified Eagle's medium containing 5\% of its normal cysteine. The medium collected was dialyzed and lyophilized. The lyophilized product was dissolved in an immunoprecipitation buffer

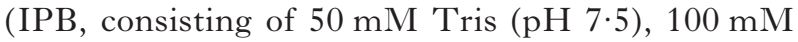
$\mathrm{NaCl}$, sodium deoxycholate $(0 \cdot 5 \%)$, SDS $(0 \cdot 1 \%)$, NP40 $(0 \cdot 5 \%)$ and $100 \mathrm{kIU} / \mathrm{ml}$ Trasylol (aprotinin; Boehringer Ingelheim Canada Ltd, Dorval, Quebec, Canada). In order to immunoprecipitate the ${ }^{35} \mathrm{~S}$-labeled $\mathrm{mPC} 1$ protein from the medium, a rabbit anti-PC1 serum (Basak et al. 1995) directed against the $\mathrm{C}$-terminal peptide sequence was used; normal rabbit serum was used as a control. The detailed procedures for immunoprecipitation, analysis by SDS-PAGE and, finally, visualization by fluorography of immunoprecipitated proteins have been described elsewhere (Shiu \& Iwasiow 1985).

\section{Western blot analysis}

Cultured cells were scraped, pelleted by centrifugation and lyzed in $50 \mathrm{mM}$ Tris- $\mathrm{HCl}$ buffer containing $20 \mathrm{mM}$ EDTA, 5\% SDS, $5 \mathrm{mM}$ $\beta$-glycerophosphate, $1 \mathrm{mM}$ AEBSF (4-(2aminoethyl)-benzenesulfonyl fluoride hydrochloride) and $70 \mathrm{kIU} / \mathrm{ml}$ aprotinin. Protein concentrations were determined by using the Bio-Rad (Hercules, CA, USA) protein assay kit. Fifty micrograms of each cell lyzate were separated on a $10 \%$ SDS-polyacrylamide gel and transferred to nitrocellulose (Bio-Rad). To detect hfurin protein, a polyclonal rabbit anti-furin antiserum (Basak et al. 1995) was used as the first antibody. The second antibody used was horseradishperoxidase-conjugated goat anti-rabbit immunoglobulin G. Visualization was accomplished using the Supersignal detection system (Pierce, Rockford, IL, USA) according to the manufacturer's instructions.

\section{Cell growth in vitro}

Electronic cell counting

Cells were plated in 24 -well plates at $1.25 \times 10^{4}$ cells/well in a medium containing $5 \%$ fetal bovine serum and allowed to attach overnight. The culture medium was then changed to serum-free medium 
supplemented with human transferrin $(10 \mu \mathrm{g} / \mathrm{ml})$ and bovine serum albumin $(200 \mu \mathrm{g} / \mathrm{ml})$ (Karey \& Sirbasku 1988). Two types of cell-culture surfaces were used: plastic, and plastic coated with the basement membrane Matrigel matrix (Becton Dickinson Labware, Franklin Lakes, NJ, USA) according to the manufacturer's protocol. After the prescribed culture period (up to 8 days), the cells were detached with trypsin (for cells on the plastic surface) or dispase (for cells on Matrigel matrix) and counted by a Coulter particle counter (Model ZBi, Coulter Electronics, Hialeah, FL, USA). For each determination, the average cell number of 4 wells was used. The cell doubling time was defined as the time (days) required for the cell number to double during the logarithmic growth phase.

\section{Crystal violet staining assay}

Cells were plated in 96-well microtiter plates at 3000 cells per well and allowed to attach overnight. The culture medium was then changed to a serum-free medium supplemented with human transferrin and bovine serum albumin, as above, as well as different concentrations of estradiol-17 $\beta$. At each time point, the crystal violet staining assay (Alfa \& Jay 1988), based on the binding of the crystal violet dye to total cellular proteins, was used. The cell-bound dye was extracted with methanol and then the absorbance at $590 \mathrm{~nm}$ was determined using an enzyme-linked immunosorbent assay plate reader (Bio-Tek Instruments, Inc., Burlington, Vermont, USA).

\section{Cell growth in vivo}

Six- to seven-week-old female BALB/c or CD-1 strain athymic nude mice, obtained from Charles River Canada (St Constant, Québec, Canada), were kept inside a laminar-flow air-filtration system. Two doses of 90-day-release estradiol pellets were used: $5 \mathrm{mg} /$ pellet (to achieve a blood level of $>900 \mathrm{pg} / \mathrm{ml}$ ), and $1.7 \mathrm{mg} /$ pellet (to achieve a blood level of $500-600 \mathrm{pg} / \mathrm{ml}$ ). Placebo pellets were used in control animals. The estradiol, placebo and tamoxifen (see later) pellets were obtained from Innovative Research of America (Sarasota, FL, USA). Each pellet was implanted subcutaneously in the dorsal midline, caudal to the neck, through a small incision which was sealed with Vetbond tissue adhesive (3M Animal Care Products, St Paul, MN, USA).

Breast cancer cells suspended at $2-5 \times 10^{6}$ cells $/ 50 \mu \mathrm{l}$ in culture medium were injected subcutaneously into the flanks of the animals, one cell type on each flank. Each experimental group contained four mice. For each experimental group, there was a corresponding group with placebo pellets implanted. Tumor volumes were monitored every 7 days by caliper measurement of the three dimensions ( $a, b, c)$ and were calculated using the formula for an ellipsoid $(v=4 / 3 \pi \mathrm{abc} / 2)$. After the final tumor measurement at the 6 th week, the estrogen pellets were removed and the tamoxifen pellets $(5.0 \mathrm{mg} /$ pellet, to achieve a blood level of $2-2.5 \mathrm{ng} / \mathrm{ml}$ ) were implanted. The tumor volumes for the subsequent 5 weeks were measured and were expressed as percentages of the tumor volume achieved prior to the removal of the estradiol pellets.

\section{Estrogen-receptor assay}

Two days prior to the harvesting of cultured cells for estrogen-receptor determination, the growth medium was changed to one that contained 5\% charcoal-stripped fetal bovine serum in order to minimize receptor occupancy owing to the presence of estrogens in fetal bovine serum. Estrogen receptors in cell lyzates were then determined by the Breast Steroid Receptor Laboratory, University of Manitoba (Winnipeg, Manitoba, Canada), using the standard ligand-binding assay (McGuire 1973).

\section{Statistical analysis}

One-way analysis of variance was used to analyze the estrogen-receptor contents of different cell types. Linear regression analysis was performed to analyze cell growth in vitro and in vivo. Statistical analyses were performed using SIGMASTAT (SPSS Inc., Chicago, IL, USA).

\section{RESULTS}

\section{Transfection and expression of proprotein convertases MPC1 and hfurin in MCF-7 human breast cancer cells}

MCF-7 cell clones surviving G-418 selection were first analyzed by Southern hybridization of genomic DNA for the integration of an intact transfected proprotein convertase cDNA (mPC1 or hfurin). Figure 1A (parts I and II) shows the hybridization of a ${ }^{32} \mathrm{P}$-labeled $\mathrm{mPC} 1 \mathrm{cDNA}$ probe to the expected 2.0 and $0.4 \mathrm{~kb}$ genomic DNA fragments in a clone positive for mPC1 cDNA integration (designated as clone PC1). A G-418-resistant clone that was transfected with the vector pcDNA3, designated as WT (clone WT) MCF-7, was included for comparison. Clone $\mathrm{PC} 1$ also expressed high levels of mPC1 mRNA (Fig. 1A, part III) when compared 
A.

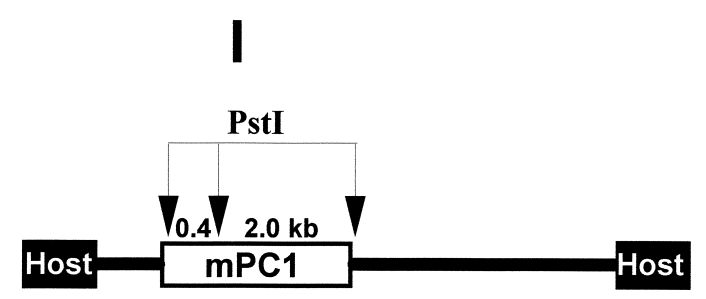

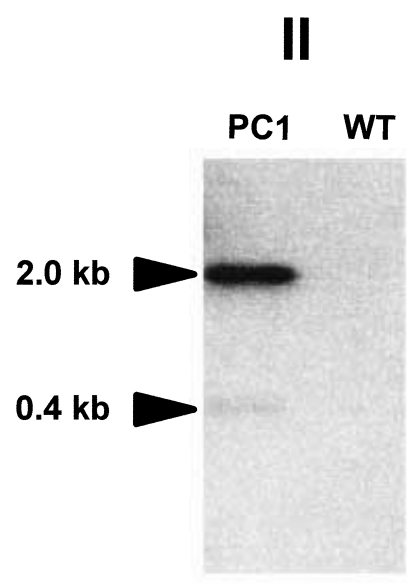

Southern

B.

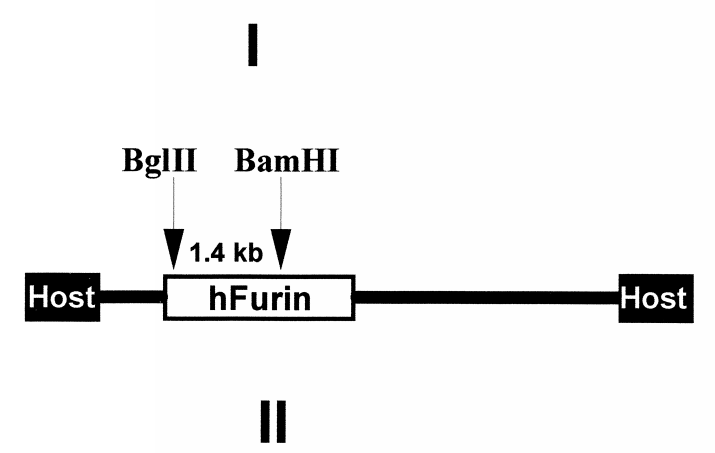

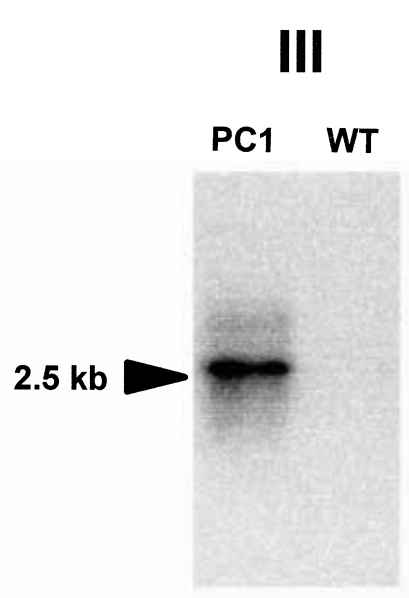

Northern

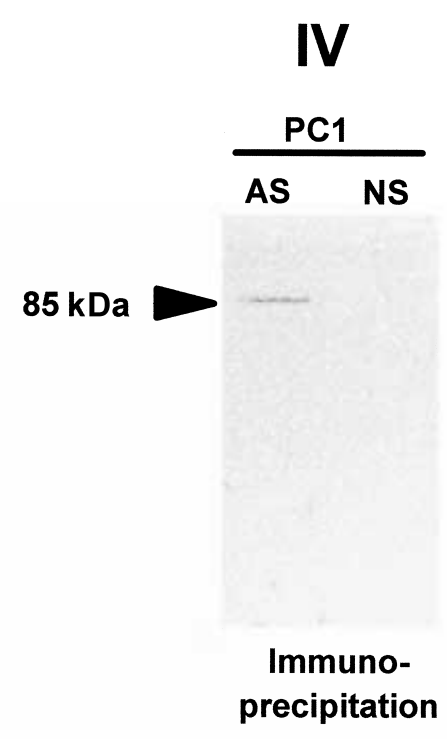

III

Furin WT

$3 \mathbf{k b}$

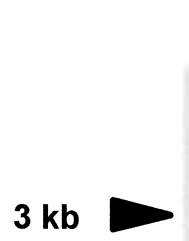

$1.4 \mathrm{~kb}$
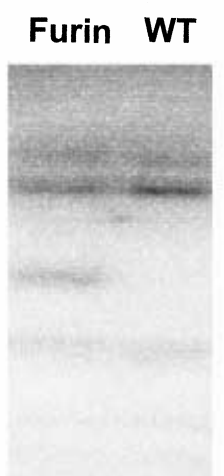

Southern
Northern

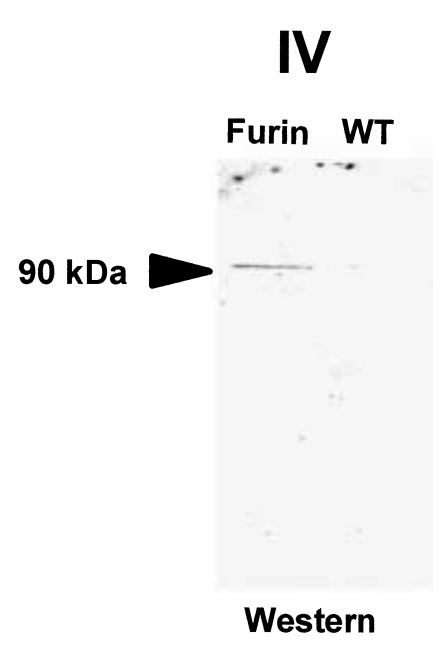

www.endocrinology.org 
with the control, clone WT. The level of endogenous human PC1 (hPC1) mRNA in clone WT was low relative to that of the transfected mPC1 mRNA in clone PC1, and was not normally detectable when total RNA was analyzed by Northern hybridization. However, the endogenous hPC1 mRNA was readily detected in MCF-7 cells by the reverse transcription/polymerase chain reaction (RT-PCR) protocol, as reported by us previously (Cheng et al. 1997). $\left[{ }^{35} \mathrm{~S}\right]$ cysteine-labeled medium of clone PC1 was subjected to immunoprecipitation using anti-PC1 antibodies. The predominant protein detected was an approximately $85 \mathrm{kDa} \mathrm{mPC} 1$ species specifically recognized by the antibodies (Fig. 1A, part IV).

MCF-7 cells transfected with hfurin cDNA were similarly analyzed for hfurin integration and expression. ${ }^{32} \mathrm{P}$-labeled hfurin cDNA was shown to hybridize to an expected $1.4 \mathrm{~kb}$ genomic DNA fragment in a G-418-resistant clone, designated as clone Furin (Fig. 1B, parts I and II). Clone Furin also expressed the expected $3.0 \mathrm{~kb}$ hfurin mRNA (Fig. $1 \mathrm{~B}$, part III). The levels of hfurin mRNA in this clone appear to be lower than those of PC1 mRNA in the PC1 clone (Fig. 1A, part III), and are consistent with the apparent lower copy number of transfected hFurin cDNA (Fig. 1B, part II) with respect to that of $\mathrm{mPC} 1 \mathrm{cDNA}$ (Fig. 1A, part II). The endogenous hfurin transcript, like the endogenous hPC1 mRNA, was low in abundance and was detected only by RT-PCR (Cheng et al. 1997) (it was not readily detected by Northern analysis of total RNA samples). When total cellular proteins were subjected to Western blot analysis, a prominent, approximately $90 \mathrm{kDa}$ furin protein was detected by the anti-hfurin antibodies in clone Furin (Fig. 1B, part IV).

\section{Morphology of mPC1 and hfurin over-expressing MCF-7 cells}

The WT MCF-7 cells growing on plastic culture dishes showed typical epithelial-like features, i.e. they were flat and polygonal. PC1- or furintransfected cells, however, demonstrated an altered morphology, in that they were more refractile and spindly, and possessed more prominent cellular processes (Fig. 2). On Matrigel-coated substratum, however, there were no obvious morphological differences among these three kinds of cells (Fig. 2). All three cell types grew in clusters that expanded in size as cell proliferation proceeded.

\section{Effect of over-expression of proprotein convertases on MCF-7 cell proliferation in vitro}

The proliferation of the PC1 and furin overexpressing MCF-7 clones (designated as clones PC1 and Furin respectively) was first compared with that of the vector-transfected, WT control MCF-7 cells (clone WT) on plastic substratum and on an extracellular matrix (Matrigel) substratum, in the presence or absence of fetal bovine serum. Table 1 shows that there were no significant differences in the growth rates of clones PC1, Furin and WT when grown in the presence of 5\% fetal bovine serum. When a serum-free medium supplemented with transferrin and bovine serum albumin was used, the doubling time of convertase-transfected clones, PC1 and Furin, was $1 \cdot 5$ times that of WT cells grown on plastic, and $2 \cdot 0$ times that of WT cells grown on Matrigel. Thus, the over-expression of PC1 or furin significantly reduced the growth rate of the human breast cancer cells MCF-7 in vitro in serum-free medium.

Since estrogenic steroids are the major growthstimulating factors normally present in fetal bovine serum and are absent in serum-free medium, we next studied the effects of estradiol- $17 \beta$ supplementation to serum-free medium on the proliferation of WT and convertase-transfected MCF-7 cells on plastic substratum. The doubling times $(\mathrm{dt})$ of the three cell types in the absence and presence of different concentrations of estradiol were recorded

FIGURE 1. (A) Detection of mPC1 integration and expression in transfected MCF-7 cells. (I) PstI restriction map of integrated mPC1 cDNA. (II) Southern analysis of PstI-digested genomic DNA revealed that the expected $2 \mathrm{~kb}$ and $0.4 \mathrm{~kb}$ bands were present in clone PC1 but not in the WT. (III) Northern analysis revealed a $2.5 \mathrm{~kb}$ mPC1 transcript in clone PC1 but not in clone WT. ${ }^{32} \mathrm{P}$-labeled mouse PC1 cDNA was used as a probe for both Southern and Northern analyses. (IV) Immunoprecipitation was carried out by incubating $\left[{ }^{35} \mathrm{~S}\right]$ cysteine-labeled proteins derived from the conditioned medium of clone PC1 with either rabbit anti-PC1 antiserum (AS) or normal rabbit serum (NS) as a control. An $85 \mathrm{kDa}$ band was precipitated with anti-PC1 antiserum. (B) Detection of hfurin integration and expression in transfected MCF-7 cells. (I) Restriction-enzyme map of the integrated hfurin cDNA. (II) Southern analysis of genomic DNA digested with BamHI and BglII, and using ${ }^{32} \mathrm{P}-$ labeled hfurin cDNA as a probe. The presence of the transfected hfurin cDNA generated the expected $1.4 \mathrm{~kb}$ band in clone Furin. The endogenous hfurin gene has yielded several additional bands common to both the Furin clone and the WT clone. (III) Northern analysis revealed the expected $3.0 \mathrm{~kb}$ transcript in clone Furin. (IV) Western blot analysis revealed a $90 \mathrm{kDa}$ protein detected by anti-hfurin antibodies in the clone Furin cells. 
WT

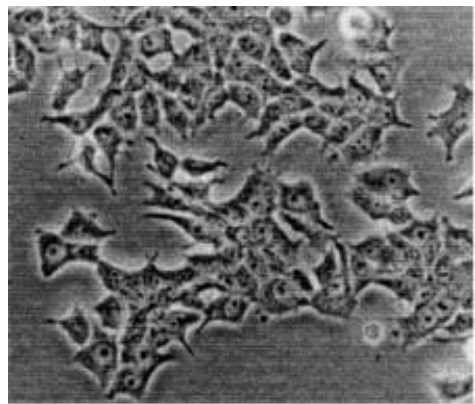

Plastic

Matrigel

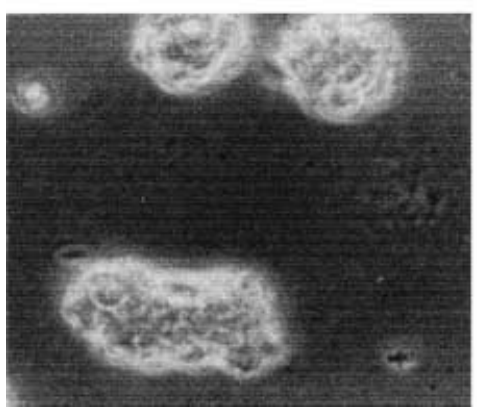

PC1
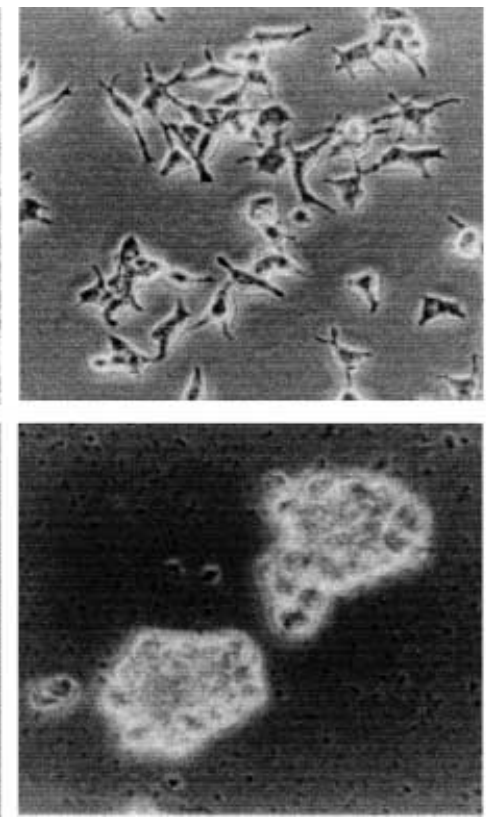

Furin
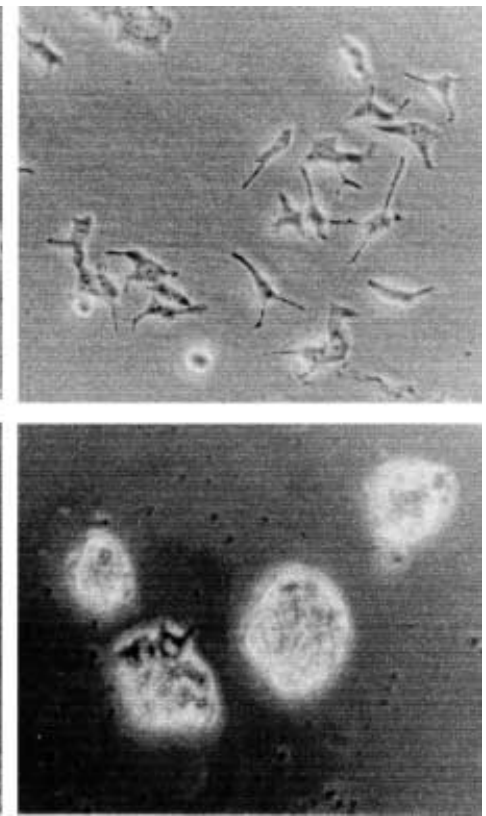

FIGURE 2. Morphology of mPC1- and hfurin-transfected MCF-7 cells. The phase-contrast photomicrographs show the appearance of clones PC1, Furin and WT cells grown on plastic and on Matrigel.

(Fig. 3). In the absence of estradiol, clone W'T $(\mathrm{dt}=2 \cdot 2$ days $)$ grew twice as fast as clones PC1 and Furin ( $\mathrm{dt}=4 \cdot 3$ days). All three cell types responded to the addition of estradiol. However, at low concentrations of estradiol $\left(<10^{-12} \mathrm{M}\right)$, the convertase-transfected clones $(\mathrm{dt}=2 \cdot 6-3 \cdot 2$ days $)$ still grew more slowly than the WT $(\mathrm{dt}=1.8$ days). At higher concentrations of estradiol $\left(>10^{-10} \mathrm{M}\right)$, the growth of PC1 and Furin was further accelerated to a rate $(\mathrm{dt}=1 \cdot 8-2 \cdot 2)$ similar to that achieved by the WT $(\mathrm{dt}=1 \cdot 8)$. Thus, convertase-transfected cells exhibited retarded growth in vitro only in the absence, or at low concentrations, of estradiol. High concentrations of estradiol were able to restore the maximal growth potential of convertase

TABLE 1. Comparison of cell growth (doubling time in days) in vitro

\begin{tabular}{|c|c|c|c|}
\hline \multicolumn{2}{|c|}{$\mathbf{5} \%$ FBS } & \multicolumn{2}{|l|}{ Serum-free } \\
\hline & Plastic & Plastic & Matrigel \\
\hline \multicolumn{4}{|c|}{ Cell type } \\
\hline W'T & $1 \cdot 9 \pm 0.03$ & $2 \cdot 58 \pm 0 \cdot 31$ & $1 \cdot 77 \pm 0 \cdot 03$ \\
\hline PC1 & $2 \cdot 1 \pm 0 \cdot 12$ & $3 \cdot 87 \pm 0 \cdot 22 *$ & $3 \cdot 18 \pm 0 \cdot 26 *$ \\
\hline Furin & $2 \cdot 3 \pm 0 \cdot 21$ & $4 \cdot 18 \pm 0 \cdot 37^{*}$ & $3 \cdot 83 \pm 0.73 *$ \\
\hline
\end{tabular}

Numbers are means \pm S.E.M. ( 3 experiments). *Denotes significant difference from clone WT; $P<0 \cdot 05$. over-expressing cells. Furthermore, this higher dependency on estrogen for growth of the convertase-transfected cells appeared not to be associated with a significant alteration in the levels of functional estrogen receptors in these clones; the estrogen-receptor contents for the WT, PC1 and Furin clones were $34 \pm 16,72 \pm 18$ and $87 \pm 47$ femtomoles per $\mathrm{mg}$ protein respectively (the differences between these values were not statistically significant; $P>0 \cdot 1)$. Finally, the growth characteristics in vitro in the presence or absence of estradiol of WT (which was transfected with a vector plasmid) cells was virtually indistinguishable from that of the non-transfected parental MCF-7 cells (data not shown), indicating that clonal selection had not resulted in phenotypic alterations of the MCF-7 cells.

\section{Growth of PC1- and furin-transfected MCF-7 cells in vivo in athymic nude mice}

Estradiol-17 $\beta$ is essential for MCF-7 cell growth in vivo in athymic nude mice (Shafie \& Grantham 1981). In the first experiment, $5.0 \mathrm{mg}$ estradiol pellets (blood level $>900 \mathrm{pg} / \mathrm{ml}$ ), were implanted subcutaneously into the nude mice. Under the influence of this high concentration of estradiol, there was no significant difference $(P>0 \cdot 2)$ between 


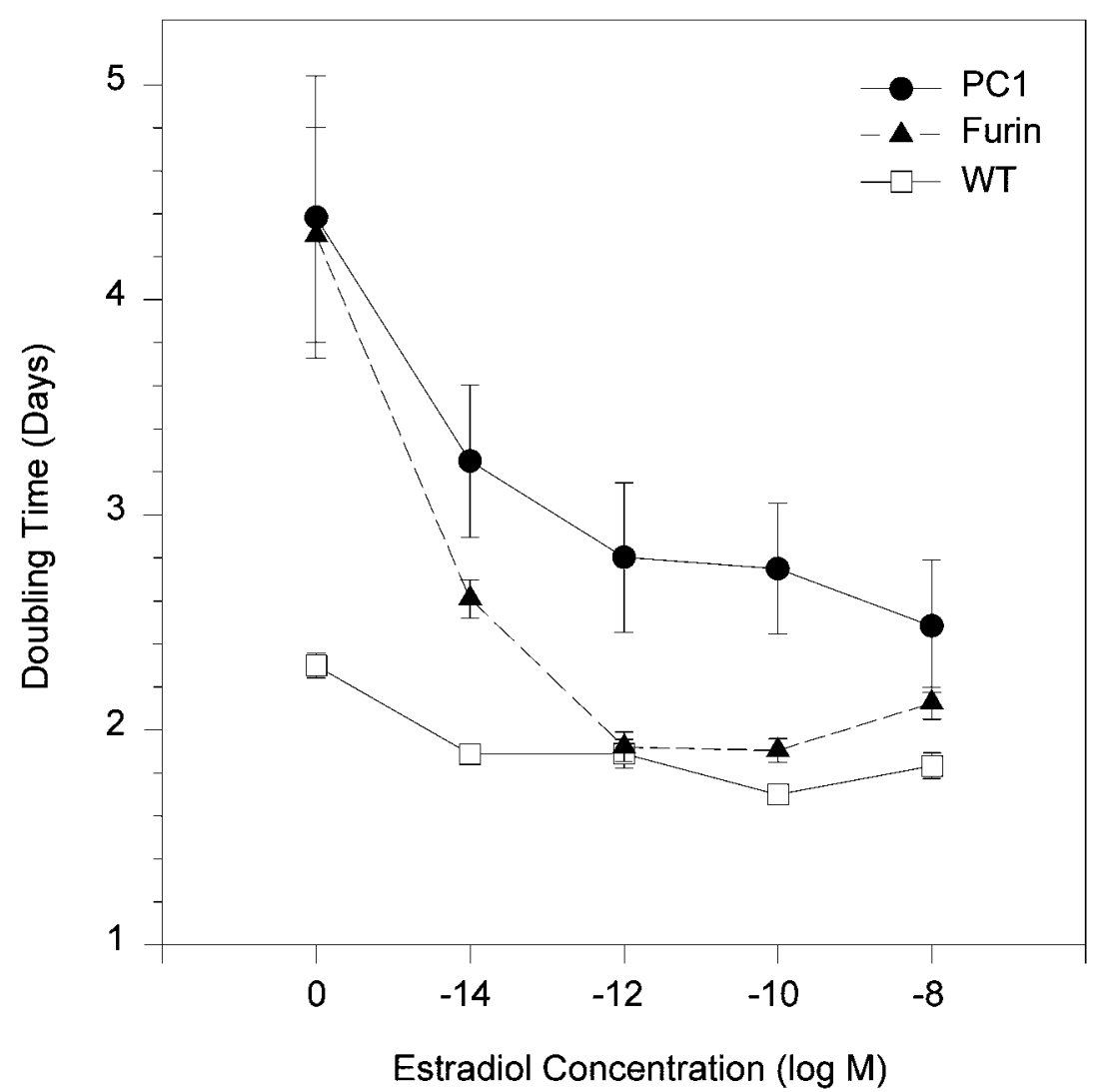

FIGURE 3. Effect of estradiol-17 $\beta$ on the proliferation of convertase over-expressing and WT MCF-7 in vitro on plastic. Population doubling times (days) were computed from the logarithmic growth phase of cells under the influence of different concentrations of estradiol. Each value represents the mean \pm S.E.M. of three independent experiments. Some of the s.E.M. bars for the WT are not visible because they are masked by the symbols.

the growth rate of WT tumors $\left(867 \pm 304 \mathrm{~mm}^{3} /\right.$ week) and PC1-transfected cells $\left(458 \pm 114 \mathrm{~mm}^{3} /\right.$ week) (Fig. 4A). When lower dose $(1.7 \mathrm{mg})$ estradiol pellets (blood level $500 \mathrm{pg} / \mathrm{ml}$ ) were used, the WT MCF-7 tumors grew at a rate $\left(585 \pm 150 \mathrm{~mm}^{3} /\right.$ week) similar to that in high-dose estradiol, but the PC1-transfected MCF-7 tumors grew more slowly $\left(93 \pm 14 \mathrm{~mm}^{3} /\right.$ week) (Fig. 4B). Consequently, there was a significant fivefold reduction $(P<0 \cdot 03)$ in the growth rate of $\mathrm{PC} 1$ over-expressing $\mathrm{MCF}-7$ tumors. In a third experiment, the growth of clone PC1 was compared with that of clone Furin in nude mice with the low-dose estradiol pellets. As shown in Fig. $4 \mathrm{C}$, there were no differences $(P>0 \cdot 5)$ between the two MCF-7 clones. Therefore, both PC1 - and furin-transfected cells grew more slowly than WT cells in vivo in nude mice in the presence of the lower dose of estradiol. All three clones failed to grow in the athymic mice implanted with placebo pellets (not shown).
The sensitivity of the established tumors to the anti-estrogen tamoxifen was also evaluated. After 6 weeks of growth, the estradiol pellets were removed and tamoxifen pellets $(5 \cdot 0 \mathrm{mg} /$ pellet; blood level 2-2.5 $\mathrm{ng} / \mathrm{ml}$ ) were implanted. The WT MCF-7 tumors regressed four times faster than PC1 - or furin-transfected tumors (Fig. 5A and B); the WT tumors decreased at a rate of $547 \mathrm{~mm}^{3} /$ week, whereas PC1- and furin-transfected tumors regressed at the rates of $71-113 \mathrm{~mm}^{3} /$ week and $134 \mathrm{~mm}^{3} /$ week respectively $(P<0 \cdot 01)$.

\section{DISCUSSION}

We have previously demonstrated, by using a sensitive RT-PCR method, that human breast cancers, when compared with normal breast tissues, exhibit elevated mRNA levels for at least four members of the proprotein convertase family - PC1, 
PC7, furin, and PACE4 (Cheng et al. 1997). In the present study, we have investigated some of the biological consequences of over-expression of PC1 and of furin in MCF-7 human breast cancer cells. $\mathrm{PC} 1$ was chosen as being representative of proprotein convertases that are localized in secretory granules and responsible for the cleavage of proteins
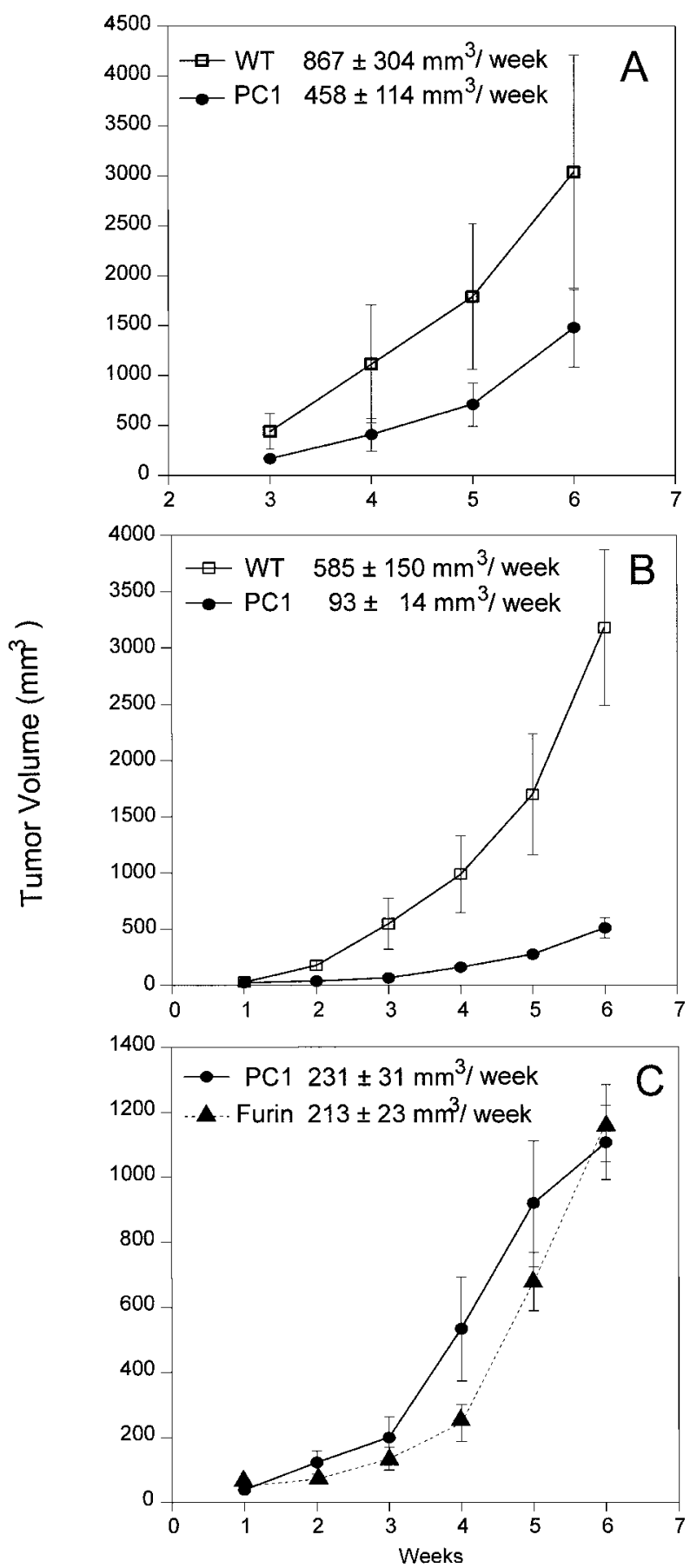

secreted by the regulated secretory pathway. Furin was chosen to represent a membrane-anchored convertase enzyme that is localized in the transGolgi network and plasma membrane, and cleaves proteins as they pass through the trans-Golgi route to be secreted by the constitutive secretory pathway (Molloy et al. 1994).

The first noticeable phenotypic change in the MCF-7 clones that over-expressed PC1 or furin was altered cell shape. The transfected MCF-7 cells have a refractile, elongated and spindle-shaped morphology, with elongated cell processes (Fig. 2) when grown on plastic substratum. The mechanisms responsible for this altered morphology are not known; however, it is possible that the excess production of $\mathrm{PC} 1$ and furin may alter the processing, and therefore functions, of important cell-adhesion proteins, perhaps including integrins, laminin, fibronectin and collagens. Indeed, furin has been shown to cleave integrin pro-alpha 3 and pro-alpha 6 subunits and is believed to be involved in the endoproteolytic processing of integrins (Lehmann et al. 1996). Thus, the altered cell adhesion and morphology seen with our convertasetransfected cells on plastic substratum may be a consequence of changes in integrin function. However, it appears that exogenously supplemented extracellular matrix proteins can compensate for the loss of function of endogenous adhesion molecules.

In addition to the morphological changes, the most striking effect of convertase over-expression in the MCF-7 breast cancer cells was on their sensitivity to hormones affecting cell proliferation. In experiments in vitro and in vivo (implants in athymic nude mice), the growth of convertasetransfected cells was less sensitive to estradiol than

FIGURE 4. Proliferation of mPC1 - and hfurintransfected and W'T MCF-7 cells in athymic nude mice receiving $5 \mathrm{mg}(\mathrm{A})$ and $1.7 \mathrm{mg}(\mathrm{B}, \mathrm{C})$ estradiol pellets. For experiments shown in (A) and (B), two million clone PC1 and WT cells were injected subcutaneously in the opposite flanks of BALB/c athymic nude mice. For the experiment shown in (C), 5 million clone PC1 and clone Furin cells were injected subcutaneously in the opposite flanks of CD1 athymic nude mice. Each point represents the mean of quadruplicate tumor volumes $\left(\mathrm{mm}^{3} \pm\right.$ S.E.M. $)$. The tumor growth rates $\left(\mathrm{mm}^{3} /\right.$ week) are shown in each panel. (A) The growth rates of WT and PC1 under the influence of $5 \mathrm{mg}$ estradiol pellets were not significantly different $(P>0 \cdot 2)$. (B) The growth rates of WT and PC1 under the influence of $1.7 \mathrm{mg}$ estradiol pellets were significantly different $(P<0 \cdot 03)$. (C) The growth rates of clones PC1 and Furin under the influence of $1.7 \mathrm{mg}$ estradiol pellets were not significantly different $(P>0 \cdot 5)$. 


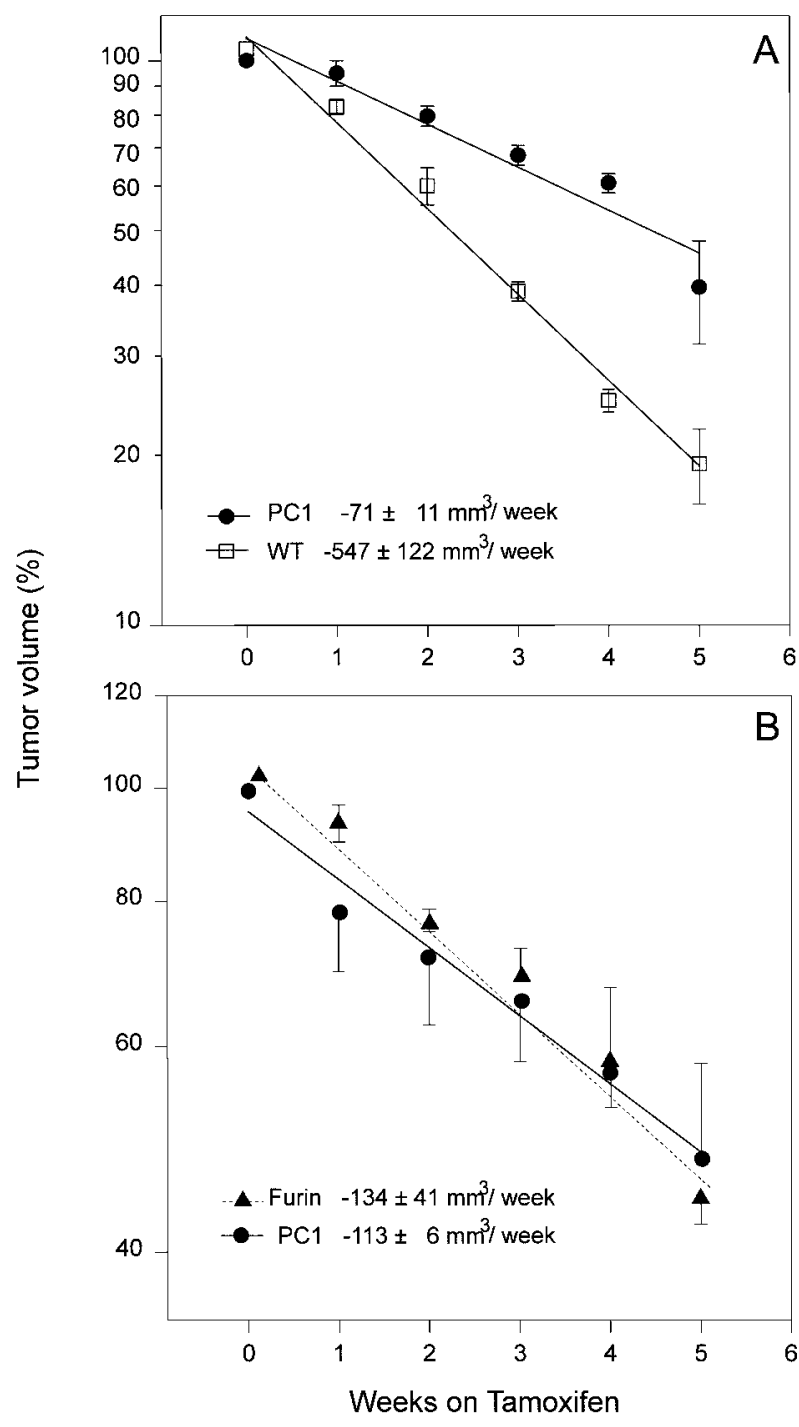

FIGURE 5. Tamoxifen-induced regression of convertase-transfected and W'T MCF-7 tumors in athymic nude mice. Tumors were allowed to grow in the presence of estradiol pellets for 6 weeks. The estradiol pellets were then removed and tamoxifen pellets

(5 mg/pellet) were implanted. The day of estradiol-pellet removal was taken as week 0 , and the tumor volume taken was considered to be $100 \%$. Each point represents the mean volume ( \pm s.E.M.) of four tumors. (A) The regression rate of $\mathrm{PC} 1$ tumors was significantly different from that of WT tumors $(P<0 \cdot 02)$. (B) The regression rate of $\mathrm{PC} 1$ tumors was not significantly different from that of Furin tumors $(P>0 \cdot 4)$.

that of WT cells. In culture, differences in growth rates between W'T and convertase-transfected cells were observed only in serum-free medium. The observation that, in serum-free medium, the convertase-transfected cells actually grew more

www.endocrinology.org slowly than WT cells is surprising, since the opposite effect would have been predicted. Whilst the mechanism accounting for this observation is not known at present, it is speculated that too much convertase could lead to excess proteolysis, and thus inactivation, of endogenous growth factors and/or cell-cycle regulators. Alternatively, over-production of convertase could activate latent growth-inhibiting molecules such as cell-cycle growth suppressors. Either one of the above scenarios would have resulted in retarded cell growth. This growth inhibition was effectively overcome by exogenously added estradiol (in serum-free medium) or serum mitogens (estrogens and peptide growth factors in serum-supplemented medium). Thus, when grown in the presence of fetal bovine serum, convertasetransfected and WT cells showed no differences in growth rate.

Whilst the WT MCF-7 tumors grew quite efficiently in the presence of low levels of estradiol, the convertase over-expressing tumors required higher levels of estradiol for maximal growth. Thus, it appears that the over-expression of proprotein convertases has rendered the breast cancer tumors more estrogen-dependent. The in vivo study also revealed that the convertase-transfected MCF-7 tumors, once established in the presence of an estradiol supplement, regressed at a rate that was one-fifth that of WT MCF-7 tumors in the presence of the anti-estrogen tamoxifen (Fig. 5). Thus, the over-expression of convertase also rendered the breast cancer cells more tamoxifen-resistant. Our observations that two independent convertasetransfected MCF-7 clones (PC1- and furintransfected) possess similar growth characteristics in vitro and in vivo in response to estradiol and tamoxifen strongly indicate that convertase expression, not clonal variation, was responsible for the observed phenotype that was clearly different from that of WT cells (both untransfected cells and cells transfected with plasmid vector).

The mechanism by which the over-expression of proprotein convertases leads to reduced estrogen sensitivity and increased tamoxifen resistance in MCF-7 cells is currently unclear. It was not due to an alteration in estrogen-receptor levels, because the estrogen-receptor contents of the WT and convertase-transfected MCF-7 cells were not quantitatively different. Since both the estrogen-induced cell proliferation and the tamoxifen-induced tumor regression involve estrogen-receptor-mediated induction of gene and cellular functions, it appears likely that the over-expression of convertases affected the activities of co-activators or corepressors of estrogen-receptor function (McKenna et al. 1999). Alternatively, the over-expression of 
convertases might have an impact on signaltransduction pathways that 'cross-talk' with the estrogen receptor (Smith 1998), leading to an alteration of estrogen-receptor functions. For example, a high level of convertase activity might produce those aberrations in receptor phosphorylation that diminish the affinity of the estrogen receptor for its ligands, estradiol and tamoxifen; such a change would result in a lower sensitivity of the convertase over-expressing cells to both the receptor agonist and the receptor antagonist. Potential alterations to estrogen-receptor modifications such as phosphorylation, and in the affinity of the receptor for its ligands, are readily testable mechanisms. Finally, it is also possible that the over-expression of proprotein convertases diminishes the activities of signal molecules downstream to the estrogen receptor. This effect would also produce a breast cancer cell population that is less sensitive to both estradiol and tamoxifen.

The present study has revealed interesting biological consequences of over-expression of proprotein convertases in cells (MCF-7) that are already transformed, and therefore the findings are relevant to breast cancer progression. However, this study has not addressed the possible role of proprotein convertase over-expression in the initiation or development of breast tumorigenesis. This issue could be addressed by transfecting in vitro normal human epithelial cells with proprotein convertases and studying the consequences. Alternatively, the potential role of proprotein convertase over-expression in the development of breast abnormality in vivo could be addressed by the use of transgenic mouse models harboring proprotein convertase genes targeted to the mammary gland.

In conclusion, the present study shows that the over-expression of proprotein convertases can profoundly influence the growth behavior of human breast cancer cells, notably in their responsiveness to estrogen and anti-estrogen actions. Clinically, proprotein convertases may be potentially useful indicators of breast cancers with high estrogen dependency and anti-estrogen resistance.

\section{ACKNOWLEDGEMENTS}

This work was supported by a grant from the US Army Medical Research and Materiel Command, Grant No. DAMD17-97-1-7319. The reading of the manuscript by Dr J A Paterson (Department of Human Anatomy and Cell Science) is very much appreciated.

\section{REFERENCES}

Alfa MJ \& Jay FT 1988 Distinct domains of recombinant human IFN- $\gamma$ responsible for anti-viral effector function. Fournal of Immunology 141 2474-2479.

Basak A, Boudreault A, Chrétien M, Seidah NG \& Lazure C 1995 Application of the multiple antigenic peptides MAP strategy to the production of prohormone convertases antibodies synthesis characterization and use of 8-branched immunogenic peptides. Fournal of Peptide Science 1 385-395.

Cheng M, Watson PH, Paterson JA, Seidah N, Chrétien M \& Shiu RPC 1997 Pro-protein convertase gene expression in human breast cancer. International Fournal of Cancer 71 966-971.

Dickson RB \& Lippman ME 1995 Growth factors in breast cancer. Endocrine Reviews 16 559-589.

Hogan BF, Constantini F \& Lacy E 1986 Isolating high molecular weight DNA. In Manipulating the Mouse Embryo: a Laboratory Manual, Section G, pp 296-298. New York: Cold Spring Harbor Laboratory.

Hubbard FC, Goodrow TL, Liu SC, Brilliant MH, Basset P, Mains RE \& Klein-Szanto AJ 1997 Expression of PACE4 in chemically induced carcinomas is associated with spindle cell tumor conversion and increased invasive ability. Cancer Research 57 5226-5231.

Karey KP \& Sirbasku DA 1988 Differential responsiveness of human breast cancer cell lines MCF-7 and T47D to growth factors and 17ß-estradiol. Cancer Research 48 4083-4092.

Lehmann M, Rigot V, Seidah NG, Marvaldi J \& Lissitzky JC 1996 Lack of integrin alpha-chain endoproteolytic cleavage in furin-deficient human colon adenocarcinoma cells LoVo. Biochemical Fournal 317 803-809.

McGuire WL 1973 Estrogen receptors in human breast cancer. Fournal of Clinical Investigation 52 73-77.

McKenna NJ, Lanz RB \& O'Malley BW 1999 Nuclear receptor coregulators: cellular and molecular biology. Endocrine Reviews 20 321-44.

Maniatis T, Fritch EF \& Sambrook J 1989 Extraction, purification and analysis of messenger RNA from eucaryotic cells. In Molecular Cloning: a Laboratory Manual, Chapter 7, pp 43-52. New York: Cold Spring Harbor Laboratory.

Mbikay M, Seidah NG \& Chrétien M 1993 From proopiomelanocortin to cancer. Possible role of convertases in neoplasia. Annals of the New York Academy of Sciences $68013-19$

Mbikay M, Sirois F, Yao J, Seidah NG \& Chrétien M 1997 Comparative analysis of expression of the proprotein convertases furin PACE4, PC1 and PC2 in human lung tumours. British Fournal of Cancer 75 1509-1514.

Meerabux J, Yaspo M-L, Roebroek AJ, Van den Ven WJM, Lister TA \& Young BD 1996 A new member of the proportein convertase gene family LPC is located at a chromosome translocation breakpoint in lymphomas. Cancer Research 56 448-451.

Molloy SS, Thomas L, VanSlyke JK, Stenberg PE \& Thomas G 1994 Intracellular trafficking and activation of the furin proprotein convertase: localization to the TGN and recycling from the cell surface. EMBO Fournal 13 18-33.

Schalken JA, Roebroek JM, Oomen PPCA, Wagenaar SS, Debruyne FMJ, Bloemers HP \& Van de Ven WJM 1987 Fur gene expression as a discriminating marker for small cell and nonsmall cell lung carcinomas. Fournal of Clinical Investigation 80 1545-1549.

Scopsi L, Gullo M, Rilke F, Martin S \& Steiner DF 1995 Proprotein convertases $\mathrm{PC} 1 / \mathrm{PC} 3$ and $\mathrm{PC} 2$ in normal and neoplastic human tissues: their use as markers of neuroendocrine differentiation. Fournal of Clinical Endocrinology and Metabolism 80 294-301. 
Seidah NG, Day R, Marcinkiewicz M \& Chrétien M 1998 Precursor convertases: an evolutionary ancient, cell-specific, combinatorial mechanism yielding diverse bioactive peptides and proteins. Annals of the New York Academy of Sciences 839 9-24.

Seidah NG, Mowla SJ, Hamelin J, Mamarbachi AM, Benjannet S, Toure BB, Basak A, Munzer JS, Marcinkiewicz J, Zhong M, Barale JC, Lazure C, Murphy RA, Chretien M \& Marcinkiewicz M 1999 Mammalian subtilisin/kexin isozyme SKI-1: a widely expressed proprotein convertase with a unique cleavage specificity and cellular localization. PNAS 96 1321-1326.

Shafie SM \& Grantham FH 1981 Role of hormones in the growth and regression of human breast cancer cells MCF-7 transplanted into athymic nude mice. Fournal of the National Cancer Institute 67 51-56.
Shiu RPC \& Iwasiow BM 1985 Prolactin-inducible proteins in human breast cancer cells. Fournal of Biological Chemistry $26011307-11313$

Smith CL 1998 Cross-talk between peptide growth factor and estrogen receptor signaling pathways. Biology of Reproduction 58 627-632.

Steeg PS 1996 Granin expectations in breast cancer? Nature Genetics 12 223-225.

Steiner DF, Smeekens SP, Ohagi S \& Chan SJ 1992 The new enzymology of precursor processing endoproteases. Fournal of Biological Chemistry 267 23435-23438.

RECEIVED IN FINAL FORM 20 November 2000 ACCEPTED 24 November 2000 